Research Article

\title{
Risk and Income Evaluation Decision Model of PPP Project Based on Fuzzy Borda Method
}

\author{
Longbo Du $\mathbb{i}^{1}$ and Jing Gao ${ }^{2}$ \\ ${ }^{1}$ Collaborative Innovation Center of Financial Service Transformation and Upgrading, School of Finance, \\ Shandong Technology and Business University, Yantai 264005, Shandong, China \\ ${ }^{2}$ School of Economics and Business, Johannes Kepler University, Linz 4040, Upper Austria, Austria \\ Correspondence should be addressed to Longbo Du; 201813669@sdtbu.edu.cn
}

Received 4 November 2020; Revised 8 December 2020; Accepted 28 December 2020; Published 20 January 2021

Academic Editor: Yi-Zhang Jiang

Copyright (C) 2021 Longbo Du and Jing Gao. This is an open access article distributed under the Creative Commons Attribution License, which permits unrestricted use, distribution, and reproduction in any medium, provided the original work is properly cited.

\begin{abstract}
In order to effectively analyze the risk-return decision-making model of PPP project by Yuan et al., (2020) this paper, based on the fuzzy Borda method and synergy effect theory, considers the synergistic effect of PPP project, constructs the model of investment risk sharing, incentive, and supervision punishment, and determines the investment risk sharing, incentive, and PPP project investment. This paper also aims to supervise and punish the decision-making mechanism to achieve the goals of the PPP project. The research results show that the increased synergy of project participants not only reduces the impact of investment risk on project revenue but also promotes project participants to increase their willingness to undertake risks, actively undertake project risks, and achieve synergy effects of PPP projects. Through the cooperation of both parties, the total income of PPP projects is increased. The research results show that the government chooses social capital participants with complementary advantages to form synergy as shown by Jiang et al. (2016); with the increase of synergy, the government needs to increase the incentive intensity, improve the performance behavior of social capital participants as proposed by Junlong et al. (2020), curb their speculation, and promote the two sides. Due to the increased synergy and the willingness of social capital participants to increase cooperation and reduce speculation, the government should reduce the intensity of supervision and punishment.
\end{abstract}

\section{Introduction}

PPP stands for the English full name "Public-PrivatePartnership," in which "Public" mainly refers to the government and "Private" mainly refers to private enterprises. This can be translated into government-enterprise cooperation, that is, public-private partnership that is an emerging project financing and project management model. This model introduces foreign capital and private capital into public infrastructure and public service projects and encourages private companies and the government to participate in the construction of public infrastructure in a cooperative manner. As early as the 1980s, China explored the application of the PPP model in the field of infrastructure. This is the first time that the government has participated in the construction of public infrastructure and public service projects through BOT (build, operate, and transfer), such as the construction of power plants, but the scale of investment is usually large. After the company invested and built an initial power plant through the BOT model, it signed a 20-year concession agreement. During this 20-year period, the company can recover the cost and profit through its own operation. 20 years later, the government regained management rights.

As an important financing means, the PPP model can comprehensively utilize the advantages of the government and the private sector [1] and establish a full-scale cooperative relationship between the government and the private enterprise, the so-called "risk sharing and benefit sharing." This model is in the construction of public infrastructure. The use of many other models does not have the advantage. In $[2,3]$, the authors propose a conceptual model that 
includes three risk dimensions and 15 SRFs to mitigate social risks and improve the social sustainability of transport PPP projects. A survey conducted to investigate stakeholder comments on the proposed SRF indicated that all SRFs are important. SRF can be used to assess social, economic, and environmental risks. Confirmatory factor analysis (CFA) validates the classification of SRFs and points out that all risk dimensions contribute to social risk. The impact of society and the environment on social sustainability may contribute more to the generation of social risks. In [4], the authors used the analytical hierarchy process to develop a generic risk assessment model; the next step was to investigate the primary purpose of early development experts' preferences for weights, rankings, and risk factor scores. The risk assessment leads to a consistent level of risk factors affecting the brownfield decision in the context of Melbourne. The results show that site-specific and project risks are the most important in brownfield development decisions. Financial, market, and planning risks are critical. Political, legal, and socioeconomic risks are relatively less important. In [5], the authors evaluated the decision-makers (DMs) responsible for maintaining the pipeline based on different perspectives of risk assessment models. It was found that this could help prioritize maintenance efforts and optimize the use of human resources and other resources. As for the transportation of natural gas through pipelines [6], the risk analysis work must consider the physical and operational characteristics of the product, the failure mode, and its consequences, depending on each unexpected situation considered. Therefore, this paper enhances previous recommendations for multicriteria decision models by using visualization tools and statistical tests that evaluate multidimensional risks. In [7], the authors construct a multistandard decision-making framework for risk assessment of construction project of image fuzzy information and propose an image fuzzy normalized projection (PFNP) model, which overcomes the existing image fuzzy projection model. This paper also establishes the entropy weight method of image fuzzy sets to calculate the standard target weight vector [8]. In the image fuzzy environment, the PFNP model is combined with the VIKOR method to construct a VIKOR method based on integrated image fuzzy normalized projection. In [9], the authors introduce a practical model to select the best and most appropriate portfolio of projects, taking into account project investment capital, returns, and risks. The article addresses the ever-changing and highly uncertain project environment by using interval type 2 fuzzy sets (IT2FS). The authors also introduce a new R\&D project evaluation model that comprehensively addresses the constraints and limitations of R\&D portfolio selection.

In recent years, the state has strengthened investment in infrastructure, which has a certain degree of mitigation of "bottleneck" constraints [10], but as the demand for infrastructure grows, China's infrastructure investment demand is growing, giving the country enormous financial pressure. China needs a lot of money to improve its infrastructure construction. It is difficult to meet the requirements of infrastructure development simply by relying on the government as an investment entity $[1,11]$. In this case, the government urgently needs to introduce a new model to alleviate the funding problem of infrastructure construction.

Aiming at the advantages of high recognition rate and good accuracy of the fuzzy Borda method, many research teams at home and abroad apply it in different fields. In [12], the authors apply the fuzzy Borda method to agriculture, develop fuzzy Borda counts to consider some ambiguities, and derive standard weights through language comparison decision criteria. The results are found in the comparison of decision criteria in multistandard decision-making (MCDM). The study extended the fuzzy Borda count to take into account the agent's confidence in its standard weight preferences [13]. These criteria include soil erodibility, hydrological sensitivities, wildlife habitats, and impervious surfaces and capture buffer-protected ecosystems in reducing soil erosion, controlling runoff generation, enhancing wildlife habitats, and mitigating storm water impacts, respectively. In [14], the authors apply the fuzzy Borda method to algorithm optimization and introduce a dynamic multiobjective optimization algorithm that integrates the cat group algorithm and the Borda count sorting method. In the proposed method, the cats of the population are sorted and classified based on the Borda selection method before and after the change. The cat with the worst Borda grade is then reinitialized to improve the diversity of the population. In addition, multiobjective cat group optimization (CSO) is applied as an aggregate-based evolutionary algorithm to converge to the optimal frontier. The simulation results show that the algorithm achieves competitive results compared with the traditional method. In [15], the authors apply the fuzzy Borda method to noise and use the weighted least squares method based on local anomaly factor (LOF) to solve the weighted fuzzy tree (WFT) algorithm. The authors validate the square method of the subsequent parameters of the fuzzy rule by two typical nonlinear examples [16]. Based on W-FT, the soft-sensor model of boiler $\mathrm{NO}_{\mathrm{x}}$ emission is established and compared with other modeling methods. It shows that the proposed W-FT algorithm can effectively identify noise and outliers, and the model based on W-FT has higher prediction accuracy and stronger generalization ability. In [17], the authors apply the fuzzy Borda method to the optimization model and propose a new interval intuitionistic fuzzy set (IVIFS) sorting function, which considers the quantity and reliability information of IVIFS and combines the TOPSIS advantage to build an optimization model to determine when the attribute weights are unknown and partially known. In addition, the authors have developed an effective method to solve the MAGDM problem, where the attribute values are represented by IVIFS. The paper studies numerical examples of supplier selection problems to prove the applicability and feasibility of the method [18]. In [19], the author uses a multirisk matrix and FMI qualitative screening methods, uses MSI evaluation criteria to establish methods, and develops effective preventive maintenance strategies based on AHP and MSI quantitative analysis methods and Borda counting method.

In order to effectively analyze the risk-return decisionmaking model of PPP projects, this paper builds a model of 
investment risk sharing, incentive, and monitoring by the fuzzy Borda number analysis method, considering the synergistic effect of PPP projects based on the PPP model and synergy effect theory, and determines PPP project. Investment risk sharing, incentives, and supervision punishment decision-making mechanisms are used to achieve the goals of the PPP project. In the process of PPP project investment risk allocation, selecting social capital participants with complementary advantages is the precondition for generating synergy effect and analyzing the synergistic effect of PPP project and the synergy effect of enterprise cooperation. Based on the enterprise cooperation output model, the total output model of the PPP project is obtained.

\section{Fuzzy Borda Algorithm and Its Application in PPP Project Risk and Return Evaluation Decision}

\subsection{PPP Mode and Related Theory}

2.1.1. PPP Mode. PPP stands for the English full name "Public-Private-Partnership," where "Public" mainly refers to the government and "Private" mainly refers to private capital. In a broad sense, the PPP model is a public goods service provided by the government departments and private capital in the form of cooperation, which is comprehensive. In a narrow sense, many countries have different translations for PPP models, such as public-private partnerships and government-enterprise partnerships.

Combined with the definition of the PPP model by international organizations and the description of PPP mode in China's Ministry of Finance in the normative documents, the meaning of the PPP model can be summarized as follows: the government and social capital sign long-term contracts with each other and participate in the whole process of partnership. In the process of public infrastructure and public service projects, with cooperation, the two parties share the responsibility of the project, share the project risks, and share the project benefits [19].

2.1.2. Game Theory. Game theory, having the English full name "Game Theory," can be literally translated as "game theory." It refers to some individuals, groups, or organizations that have conflicts of interest under certain rules and constraints, according to their own information conditions, simultaneously or sequentially. Whether it is one or multiple policy choices, each choice will eventually get a corresponding result. In this process, when one of the parties chooses the strategy, it will be affected by other parties, and the party will eventually influence the decision-making behavior of other parties regardless of the decision made. Therefore, game theory is also called "the game theory" [3].

2.1.3. Cooperative Game. The cooperative game refers to the game in which the parties involved in the project conduct cooperation and alliance. Cooperative gaming can at least increase the interests of one party, and sometimes even create benefits for both parties. This also increases the interests of the entire society to a certain extent, so it is also called a positive game. The existence of a cooperative game must meet the following basic conditions: first, for the alliance, the total benefit obtained after the cooperation is greater than the sum of the benefits obtained by each participant when operating alone; secondly, there should be participants who can get more income distribution rules than when they do not join the league. In the cooperative game, the two sides mainly adopt a cooperative approach to enhance the interests of both parties, emphasizing team rationality and maximizing collective interests [20]. The prerequisite for cooperation is the fair and equitable distribution of interests.

2.1.4. Synergies. The synergy effect of PPP refers to the government's choice of social capital participants with management advantages to cooperate; the government handles political, economic, and social risks, and the social capital participants provide capital and management experience and use the complementary advantages of both parties to form synergy. In the preproject construction period and operation period, the complementary advantages of government and social capital participants are integrated and a reasonable organization is established through clear government roles and responsibilities, coordination and communication among organizations are strengthened, and a reasonable risk-sharing mechanism is established. Also, the incentive mechanism promotes synergy between the two to achieve the objectives of management coordination, financial coordination, and operational synergy of PPP projects.

2.2. Fuzzy Based on Grid Acquisition Borda Number Analysis. Suppose the expert scores the $m$ th attribute of the indicator $C_{p}: B_{m} C_{p}$, where $m=1,2, \ldots, M$, representing the $m$ th attribute of the element, and $p=1,2, \ldots, N$, indicating the $p$ th indicator.

2.2.1. Determining the Degree of Membership of Each Indicator. In the $m$ th evaluation index, each evaluation index $C_{p}$ is calculated to belong to the most important membership degree $U_{m p}$, where $U_{m p}=B_{m} \quad\left(C_{p}\right) /$ $\max \left\{B_{m}\left(C_{p}\right)\right\} \quad\left(0 \leq U_{m p} \leq 1\right)$

$$
\begin{aligned}
f_{h p} & =\sum_{m=1}^{M} \delta_{m}^{h}\left(C_{p}\right) U_{m p}, \\
R_{p} & =\sum_{h} f_{h p} .
\end{aligned}
$$

In equation (1), $f_{h p}$ is the frequency of each indicator ambiguity, $R_{p}$ is the sum of the index, $C_{p}$ indicates the fuzzy frequencies, and $\delta_{m}^{h}\left(C_{p}\right)$ is the sparse degree of the priority relationship of each indicator. For $\delta_{m}^{h}\left(C_{p}\right)$ to make the following definition, the $m$ th attribute of the element is sorted according to the size and the order relationship of the attribute is obtained. If the index $C_{p}$ ranks $h$ in this order relationship, then $\delta_{m}^{h}\left(C_{p}\right)=1$; otherwise, $\delta_{m}^{h}\left(C_{p}\right)=0$. 
Also, when the index $C_{i}$ and the index $C_{j}$ are the same as the index membership degree $U_{m p}$ in the order relationship of the $m$ th attribute of the element, that is, the ranking of the two indicators in the priority relationship is juxtaposed as $h$, at this time, $\delta_{m}^{h}\left(C_{i}\right)=\delta_{m}^{h}\left(C_{j}\right)=(1 / 2)$. Similarly, if three indicators, $C_{i}, C_{j}$, and $C_{k}$, are in the order relationship of the $m$ th attribute, i.e., the ranking is $h$, then $\delta_{m}^{h}\left(C_{i}\right)=\delta_{m}^{h}\left(C_{j}\right)=$ $\delta_{m}^{h}\left(C_{j}\right)=(1 / 3)$ is defined, and so on.

The calculation of the fuzzy Borda number $\mathrm{FB}(\mathrm{pC})$ is performed as follows: the definition $Q_{h}=(1 / 2)(N-h)(N-$ $h+1)$ is used to indicate the weight of each evaluation index $C_{p}$; when it ranks $h$ in the order relationship of the attribute, then the calculation formula of the fuzzy Borda number $\operatorname{FB}\left(C_{p}\right)$ can be obtained, as follows:

$$
\operatorname{FB}\left(C_{p}\right)=\sum_{h}\left(\frac{f_{h p}}{R_{p}}\right) Q_{h}=\sum_{h} W_{h p} Q_{h} .
$$

Among them, $W_{h p}=\left(f_{h p} / R_{p}\right)$. The fuzzy Borda number $\mathrm{FB}(\mathrm{Cp})$ of each index obtained is normalized, and the weight values of each evaluation index are obtained as follows:

$$
W_{p}=\frac{\operatorname{FB}\left(C_{p}\right)}{\sum_{p=1}^{N} \operatorname{FB}\left(C_{p}\right)} .
$$

At this point, the weights of the evaluation indicators at all levels can be calculated.

\subsection{Risk-Sharing Model of PPP Project Based on Fuzzy Borda Method}

\subsubsection{Model Assumptions}

Hypothesis 1. The variance of the return on investment risk is $\sigma 2$, indicating the degree of impact of investment risk on project income. The government's rate of return variance $(\sigma 1)$ and the social capital participant's rate of return variance $(\sigma 2)$ reflect the uncertainty of the return of the risk when the two parties independently bear the risk, indicating the degree of impact of the investment risk on the participants' income as a measure of project participation.

The same type of risk is treated and the variance of the yield of each project participant on the premise of a certain income is compared. The party with the largest variance, that is, the degree of influence of the risk on the participants' income, indicates that the party's risk control ability is smaller.

Hypothesis 2. $F\left(\sigma_{1}, \sigma_{2}\right)$ reflects the impact of the synergy between the government and social capital participants on investment risk.

$$
F\left(\sigma_{1}, \sigma_{2}\right)=2 \rho \sigma_{1} \sigma_{2} x y
$$

where $\rho$ is the value $[-1,0) . \rho$ represents the degree of complementarity of risk management and control capabilities among project participants. The risk management and control between project participants can be more complementary, that is, the smaller the $\rho$ value, the greater the synergy. Since PPP projects adopt a "limited recourse" financing model, $x$ and $y$, respectively, represent the proportion of risk taken by the government and social capital participants.

2.3.2. Model Construction. Through the cooperation of both parties, the project investment risk is dealt with, and the risk has little effect on the project's revenue. The model is as follows:

$$
\begin{aligned}
\min \sigma^{2} & =\sigma_{1}^{2} x^{2}+\sigma_{2}^{2} y^{2}+2 \rho \sigma_{1} \sigma_{2} x y, \\
s t x+y & =1, \\
x & =\frac{\sigma_{2}^{2}-\rho \sigma_{1} \sigma_{2}}{\sigma_{1}^{2}+\sigma_{2}^{2}-2 \rho \sigma_{1} \sigma_{2}}, \\
y & =\frac{\sigma_{1}^{2}-\rho \sigma_{1} \sigma_{2}}{\sigma_{1}^{2}+\sigma_{2}^{2}-2 \rho \sigma_{1} \sigma_{2}} .
\end{aligned}
$$

In the case of complementary risk management and control capabilities, the synergy of project participants can have an impact on investment risk allocation. When $\rho=0$, the respective risks are independent and the result is as follows:

$$
\sigma^{2}=\frac{\sigma_{1}^{2} \sigma_{2}^{2}}{\sigma_{1}^{2}+\sigma_{2}^{2}}
$$

When $-1<\rho<0$, the risk management and control ability of the government and social capital participants are strong, and as $\rho$ decreases, the degree of complementarity increases and the synergy capacity increases. That is, the government has the advantages of coordination, organization, and credibility, lacking technical and operational management advantages, and social capital participants have a comparative advantage on the government's shortboard. And, because of the risk loss $\sigma^{2}<\left(\sigma_{1} x+\sigma_{2} y\right)^{2}$ after cooperation, $\sigma<\left(\sigma_{1} x+\sigma_{2} y\right)$, indicating that the total risk after the cooperation between the government and social capital participants is less than the goal of achieving " $1+1>2$ " before the cooperation. Through the cooperation of both parties, the impact of investment risk is reduced.

When $-1<\rho<0$, as the degree of complementarity of risk management and control increases (the smaller the value of $\rho$ ), the synergy capacity increases and the impact of investment risk on project returns decreases.

$$
\frac{\partial \sigma^{2}}{\partial \rho}=\frac{2 \sigma_{1}^{2} \sigma_{2}^{2}\left(\sigma_{1} \sigma_{2}+\rho^{2} \sigma_{1} \sigma_{2}-\rho \sigma_{1}^{2}-\rho \sigma_{2}^{2}\right)}{\left(\sigma_{1}^{2}+\sigma_{2}^{2}-2 \rho \sigma_{1} \sigma_{2}\right)^{2}} .
$$

This explain that when the government chooses social capital participants with strong complementary advantages, the greater the degree of complementarity between the two parties, the greater the synergy ability. The project participants actively deal with the investment risks of the project and the impact of investment risks on PPP projects. This requires the government to evaluate the social capital 
participants involved in the bidding during the bidding stage and select social capital participants with strong complementary strengths and strong synergies with the government.

\section{Construction of PPP Project Risk and Return Evaluation Decision Model Based on the Fuzzy Borda Method}

\subsection{Data Source}

(1) Select Members of the Expert Group. In the process of optimizing the key risk factors of the PPP project, the selected experts require an in-depth understanding of the PPP project and have a certain practical experience to ensure the quality of the recognition results. In addition, we must select the appropriate proportion of experts from the front line of senior management personnel, scientific research institutions, and other experts to ensure the comprehensive understanding of experts. There are 8 members of the expert group, including 2 senior management personnel in the first line of the project, 3 professors/teachers (engineering project management direction) in the research institutes, and 3 government department staff with PPP project experience.

(2) Design and Issue Questionnaires. Design questionnaires (Table 1 is the evaluation level, judgment basis, and quasi-family quantification) issue the questionnaire to the experts and ask the experts to answer separately.

(3) Multiple Rounds of Investigation by Experts. The investigators conducted the statistical analysis of the expert questionnaires and sent the summary results together with the next round of questionnaires to the experts. The experts conducted a new round of questionnaires based on other expert opinions. The investigators collected opinions again for statistical induction. After repeated operations, the expert opinions gradually converge until $P<0.05$.

\subsection{Evaluation Criteria}

3.2.1. Judgment Matrix Construction Method. This paper proposes a new form of evaluation matrix, which contains the information of each expert, in order to calculate the accuracy of the expert opinions. The matrix form is shown in Table 2.

Among them, $x i j$ represents the evaluation level of the factor $h i$ by the expert $h i$. Considering the hesitation, uncertainty, and other psychological states that may exist in the evaluation of experts, the single evaluation value is often difficult to give. In order to make the experts have more expression space, this paper evaluates the form of interval number $[a i j, b i j]$ and represents $x i j$ as follows:

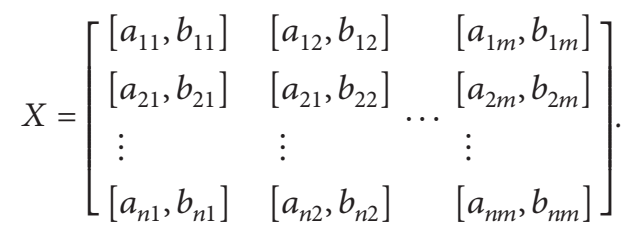

$[a i j, b i j]$ is an expert's analysis of the expectations and status quo of the evaluation items, and the range of the evaluation of the ranks between 1 and 5 levels. This form of expressing opinions or results in interval numbers can better reflect the ambiguity and uncertainty of information. At the same time, the use of this form in data processing can reduce the loss of fuzzy information.

\subsubsection{Calculating the Weight of the Indicator}

(1) Calculate the product $M i$ of each row element of the judgment matrix $A$, and the formula is

$$
M_{i}=\prod_{j=1}^{n} a_{i j}, \quad i=1,2,3, \cdots, n .
$$

(2) Calculate the $n$th root value $W_{i}=\sqrt[n]{M_{i}}, \quad i=$ $123, \ldots, n$ of each line Mi. In the test, $n$ is the order of the matrix.

(3) Normalize the $W i$ and obtain the weight of the indicator $\mathrm{Zi}$. The calculated formula is

$$
Z_{i}=\frac{W_{i}}{\sum_{i=1}^{n} W_{i}}
$$

(4) Calculate the maximum eigenvalue $\lambda_{\max }$ of the judgment matrix.

$$
\lambda_{\max }=\sum_{i=1}^{n} \frac{(A \cdot W)_{i}}{n W_{i}} .
$$

\subsubsection{Standardization of Indicator Data}

Standardization formula for benefit indicators is as follows:

$$
\begin{array}{r}
r_{i j}=\left(b_{i j}-\min _{j} b_{i j}\right) /\left(\max _{j} b_{i j}-\min _{j} b_{i j}\right), \\
i=1,2,3 \cdots m, \\
j=1,2,3 \cdots n .
\end{array}
$$

Standardization formula for cost-type indicators is as follows:

$$
\begin{array}{r}
r_{i j}=\left(\max _{j} b_{i j}-b_{i j}\right) /\left(\max _{j} b_{i j}-\min _{j} b_{i j}\right), \\
i=1,2,3 \cdots m_{j}, \\
j=1,2,3 \cdots n .
\end{array}
$$

Fixed-type indicator standardization formula is as follows: 
TABLe 1: Quantification table of evaluation level, judgment basis, and familiarity.

\begin{tabular}{lccccc}
\hline Evaluation level & Level quantized value & Judgments based & Judging the quantized value & Familiarity & $\begin{array}{c}\text { Familiarity quantified } \\
\text { value }\end{array}$ \\
\hline Very important & 7 & Experience & 0.8 & Very familiar & 1 \\
More important & 8 & Theoretical analysis & 0.6 & More familiar & 0.8 \\
Important & 6 & Peer understanding & 0.4 & Familiar & 0.6 \\
Not so important & 4 & Intuitive judgment & 0.2 & Not so familiar & 0.4 \\
Unimportant & 2 & & & Unfamiliar & 0.2 \\
\hline
\end{tabular}

TABLE 2: New evaluation matrix form.

\begin{tabular}{|c|c|c|c|c|c|c|}
\hline \multirow{2}{*}{ Expert set } & \multicolumn{6}{|c|}{ Factor set } \\
\hline & $f 1$ & $f 2$ & $\ldots$ & fj & $\ldots$ & $\mathrm{fm}$ \\
\hline$h 1$ & $X 11$ & $X 12$ & $\ldots$ & $X 1 j$ & $\ldots$ & $X 1 m$ \\
\hline$h 2$ & $X 21$ & $X 22$ & $\ldots$ & $X 2 j$ & $\ldots$ & $X 2 m$ \\
\hline$\ldots$ & $\ldots$ & $\ldots$ & $\ldots$ & $\ldots$ & $\ldots$ & $\ldots$ \\
\hline $\mathrm{Hi}$ & $X i 1$ & $\mathrm{Xi2}$ & $\ldots$ & $X i j$ & $\ldots$ & Xim \\
\hline$\ldots$ & $\ldots$ & $\ldots$ & $\ldots$ & $\ldots$ & $\ldots$ & $\ldots$ \\
\hline$H n$ & $X n 1$ & $X n 2$ & $\ldots$ & $X n \mathrm{j}$ & $\ldots$ & $X n m$ \\
\hline
\end{tabular}

$$
\begin{aligned}
& r_{i j}=1-\left|b_{i j}-T_{i}\right| / \max _{j}\left|b_{i j}-b_{i}\right| \\
& i=1,2,3 \cdots, \\
& n, j=1,2,3, \cdots m .
\end{aligned}
$$

Deviation-type index standardization formula is as follows:

$$
\begin{array}{r}
r_{i j}=\left(b_{i j}-U_{i}\left|-, \min _{j}\right| b_{i j}-U_{i} \mid\right) / \\
\left(\max _{j}\left|b_{i j}-U_{i}\right|-\min _{j}\left|b_{i j}-U_{i}\right|\right), i=1,2,3, \cdots m .
\end{array}
$$

Interval indicator standardization formula is as follows:

$$
r_{i j}= \begin{cases}1-\frac{\max \left\{q_{1}^{i}-b_{i j}, b_{i j}-q_{2}^{i}\right\}}{\max \left\{q_{1}^{i}-\min b_{i j}, \max _{j} b_{i j}-q_{2}^{i}\right\}}, & \text { if } b_{i j} \notin\left[q_{1}^{i}, q_{2}^{i}\right] \\ 1 & \text { if } b_{i j} \in\left[q_{1}^{i}, q_{2}^{i}\right]\end{cases}
$$

\section{Modeling Results of PPP Project Risk and Return Evaluation Decision Based on the Fuzzy Borda Method}

4.1. PPP Project Model Results Based on Model Borda MethodRisk Sharing. In order to better understand the investment risk allocation problem of PPP projects, the following example is used to verify the correctness of the conclusion. In the case of parameters $\sigma 1=1$ and $\sigma 2=1$, Figure 1 simulates the impact of project participants' synergy on the investment risk of PPP projects. The greater the capacity of synergies, the more the risk management capacity between the government and the stakeholders of social capital added, the smaller the impact of the investment risk of a PPP project. Figure 2 simulates the impact of project participants' synergies and risk ratios on risk sharing. The simulation results show that the government's risk-sharing ratio decreases as the government's risk ratio to social capital participants increases. It can also be seen that when $m=2$, the government's risk-sharing ratio decreases with the increase of synergy ability (the smaller the value of $\rho$ ), but it fails to accurately identify the synergy ability of $m<2$ to the government's risk-sharing ratio. On the basis of Figures 1 and 2, we simulate the relationship between the government's risksharing ratio and its risk loss in the case of the parameter $\sigma 2=1$, simulating $\rho=-1, \rho=-0.5$, and $\rho=0$.

Figure 2 shows that as the government's risk-return variance increases, it shows that the smaller the government's risk control ability, the smaller the proportion of its investment risk and the principle of risk sharing of PPP projects. In Figure 2, when $\sigma 2>\sigma 1$, as the synergistic energy increases (the smaller the value of $\rho$ ), social capital participants take risks and help governments share certain risks. When $\sigma 2<\sigma 1$, the smaller the synergy value, the higher the willingness to take risks in the government's cooperation process and the willingness to help social capital participants 


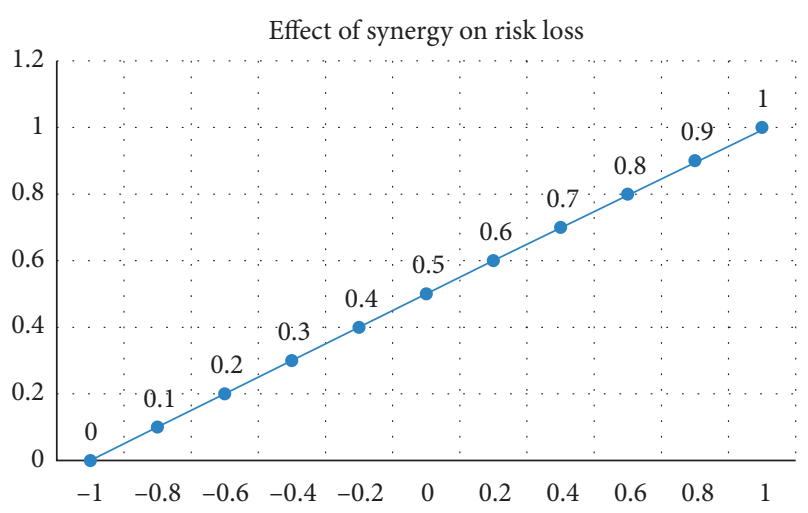

Figure 1: Effect of synergy on risk loss.

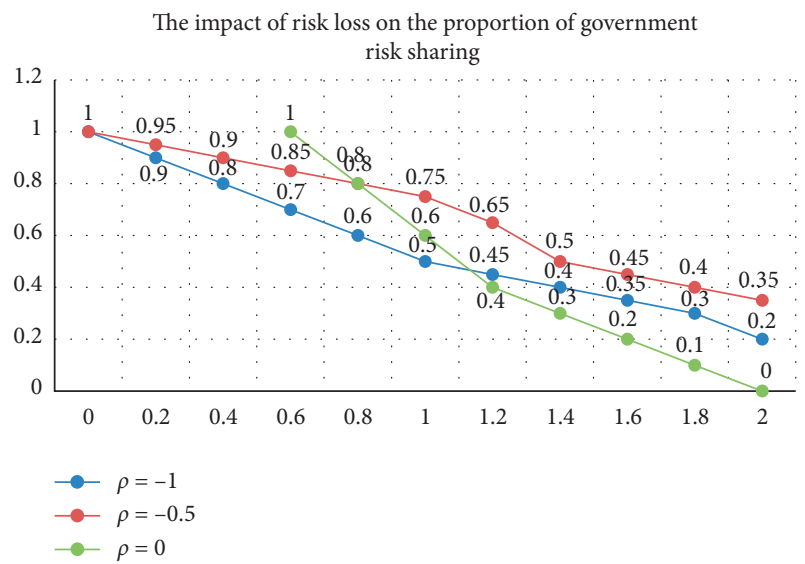

FIGURE 2: Impact of risk loss on the proportion of government risk sharing.

participate in the risk. Figure 2 can also observe that the government's risk-sharing ratio decreases with the government's risk control ability, which indicates that the risk assumed should be within the risk control ability of the project participants.

4.2. PPP Project Model Results Based on the Fuzzy Borda Method: Incentive. The following example is used to verify the accuracy of the conclusions of PPP project synergy and to analyze the impact of the cooperation between the government and social capital participants on the overall income of PPP projects and the impact on the behavior of social capital participants. In the case where the parameters $b 1=1, b=1.5, \rho=0.8$, and $\sigma=0.7$ are fixed, the effects of the synergistic effect coefficient on the incentives, the efforts of the project participants, the speculative behavior of the social capital participants, and the income of the PPP project are analyzed.

Figure 3 shows that the government's Pareto optimal effort level increases as the synergy coefficient increases; the social capital participants' efforts increase as the synergy coefficient increases; the government's incentives for social capital participants follow synergy. The effect coefficient increases and increases.

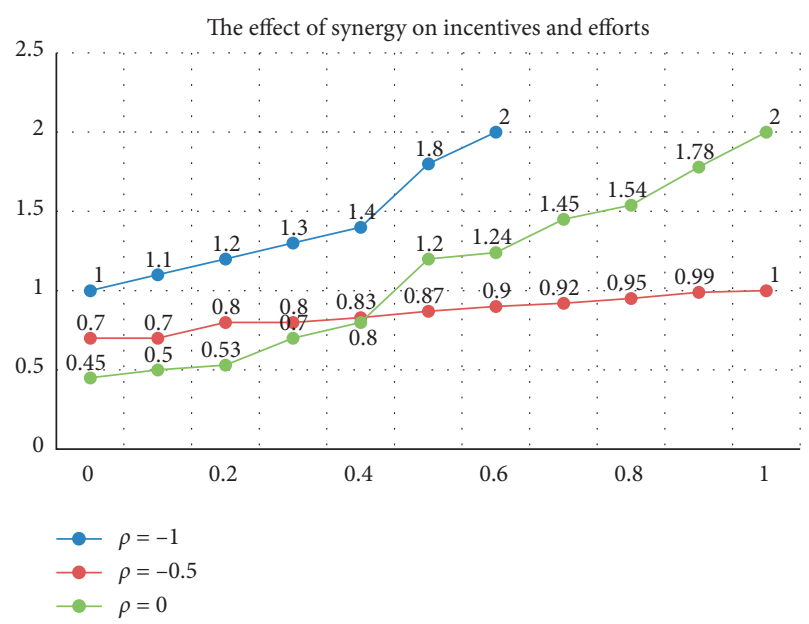

Figure 3: The impact of synergies on incentives and efforts.

Figure 4 shows that as the synergy coefficient increases, the efforts of social capital participants are getting closer to the Pareto optimal effort level. Due to information asymmetry, the government cannot fully grasp the information of social capital participants. Social capital participants take speculation for their own economic interests, violating the willingness of cooperation between the government and social capital participants and impairing the overall PPP project. However, as the synergy between the government and social capital participants increases, the willingness to cooperate among social capital participants increases, reducing the possibility of speculative behavior by social capital participants. Figure 4 shows that the total return of the PPP project increases as the synergy coefficient increases. Looking at Figure 4, through the synergy between the two parties, increasing the total income of the PPP project will not only attract social capital participants to enter the PPP project but also ease the government's debt pressure and achieve a win-win situation.

4.3. PPP Project Model Results Based on Fuzzy Borda MethodSupervision Punishment. The following example is used to verify the accuracy of the conclusions of the PPP project synergy. In the case where the parameters $b 1=1, b=1.5$, $\rho=0.8, \sigma=0.7, d=0.5, L=1$, and $M=2$ are fixed, the reliability of the conclusions herein is verified.

Figure 5(a) shows that the government's incentive intensity increases with the increase of the synergy coefficient, and as the government's punishment increases, the social capital participants' compliance efforts increase with the synergy coefficient. Figure 5(b) shows that the speculative behavior of social capital participants decreases with the increase of the synergy coefficient and decreases with the increase of government punishment. The government's supervision intensity increases with the synergy coefficient. It first increases and then decreases as the government's punishment increases. The threshold value of the penalty force in Figure 5 decreases as the synergy coefficient increases. 


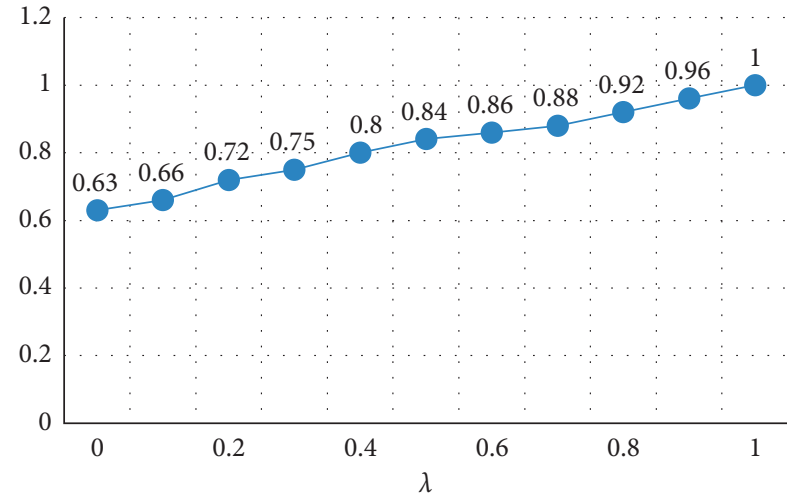

(a)

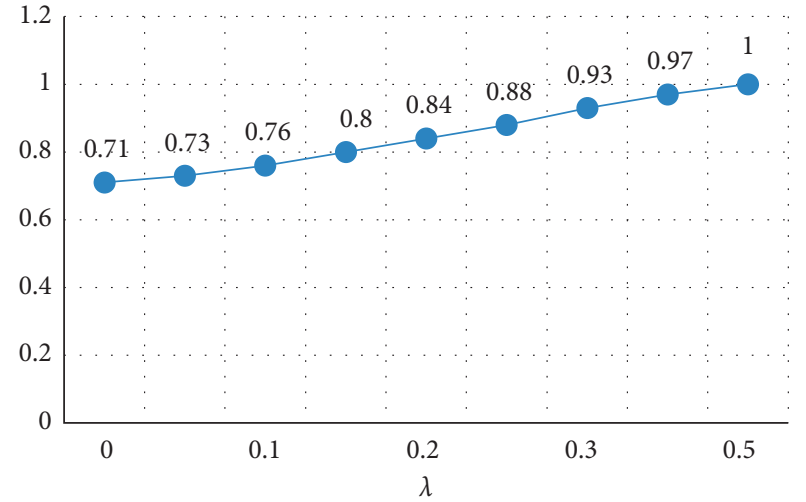

(b)

FIGURE 4: Interaction diagram of synergy. (a) Impact on social moral hazard. (b) Impact on PPP project income.

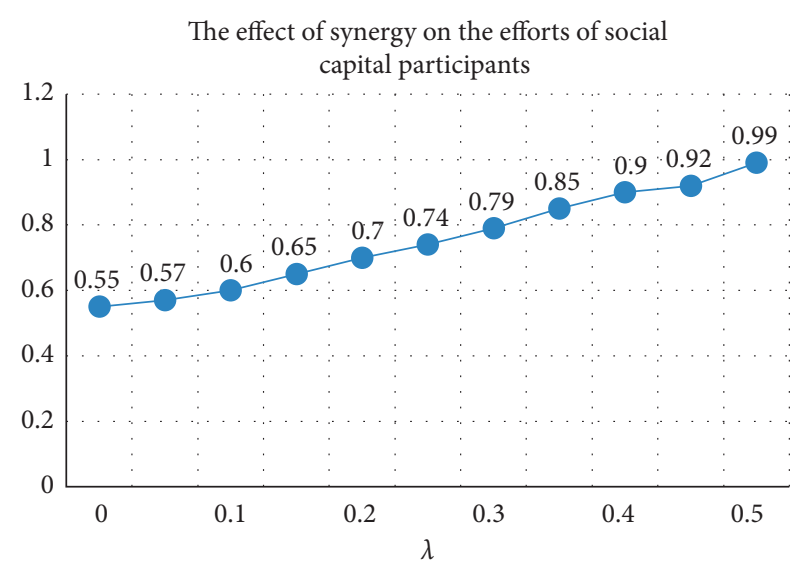

(a)

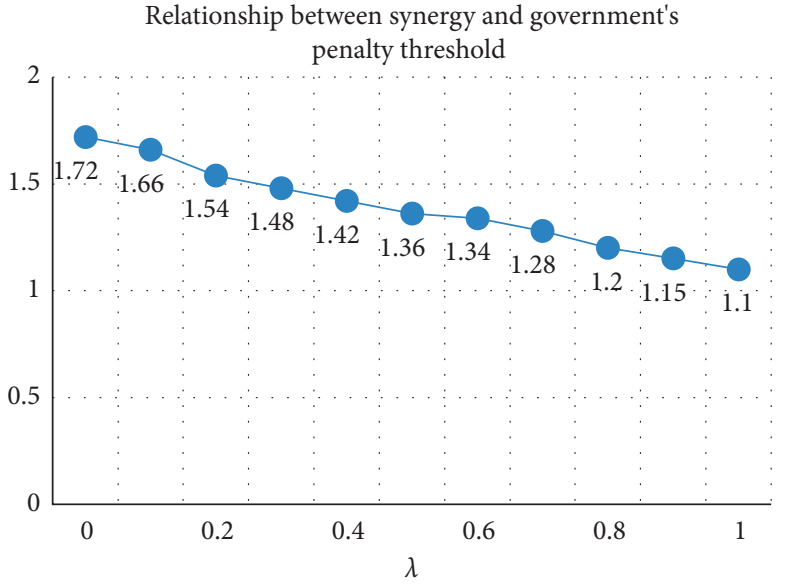

(b)

Figure 5: Synergy and government relationship diagram. (a) Punishment and government supervision. (b) Government penalty threshold.

From the above research, we can find that choosing the right social capital participants and constructing a reasonable supervision mechanism can achieve the goal and promote cooperation between the two parties. This paper comprehensively considers the efforts of both parties and the synergy effect of PPP projects based on principal-agent theory, divides the efforts of social capital participants into performance behaviors and speculation behaviors, introduces the government's supervision and punishment, and builds a PPP project supervision and punishment model based on synergy effect, setting up an effective supervision and punishment mechanism to achieve the goal.

\section{Discussion}

Through the above analysis of the nature of the PPP project, the government selects social capital participants with complementary advantages to form a cooperative relationship. The government relies on the funds of the social capital participants to ease its financial pressure and uses the management means of the social capital participants to save costs and increase project returns, to deal with some investment risks through the market means of social capital participants, and, to a certain extent, to help the government achieve the social benefits of the project.

The reasonable risk sharing of the project must ensure that the benefits of the project participants after the cooperation are greater than the benefits before the cooperation so that the social capital participants can enter the PPP project and achieve the synergy between the two parties. Reasonable risk sharing not only needs to meet the interests of project participants but also needs to meet the risk control ability of the project participants and the ability of the two parties to cooperate, so as to ensure the long-term effectiveness of the cooperation between the two parties. The synergy effect of PPP projects stems from the cooperation of the government and social capital participants with synergistic capabilities. When selecting the social capital participants, the government should focus on the lack of government; but, at the same time, it can promote the success of PPP projects, thus achieving financial coordination, management coordination, and operational synergy 
of PPP projects, reducing project costs, and improving efficiency.

The research results show that the government chooses social capital participants with complementary advantages to form synergy; with the increase of synergy, the government needs to increase the incentive intensity, improve the performance behavior of social capital participants, curb their speculation, and promote the two sides. Due to the increased synergy and the willingness of social capital participants to increase cooperation and reduce speculation, the government should reduce the intensity of supervision and punishment. In the process of allocating investment risks of PPP projects, it is necessary to minimize the impact of investment risks on earnings under the established income. By analyzing the risktaking ability of the government and social capital participants and the synergistic ability formed by complementary risk management and control capabilities, the project participants' investment risk allocation ratio is determined and the project risk-sharing goal is achieved.

\section{Conclusions}

Based on the fuzzy Borda method and the synergistic effect theory, this paper considers the synergistic effect of PPP projects, constructs a model of investment risk sharing, incentive, and supervision punishment, determines the investment risk sharing, incentive, and supervision penalty decision mechanism of PPP project, and realizes the goal of PPP project. The study is concluded as follows:

(1) Choosing social capital participation with complementary advantages in the process of allocating investment risk to PPP projects is a prerequisite for creating synergies. In this article, we will comprehensively consider the synergistic effects between the government and social capital participation and set up a risk allocation model for investing in PPP projects that produce synergistic effects. The research results show that the increased synergy of project participants not only reduces the impact of investment risk on project revenue but also promotes project participants to increase their willingness to undertake risks, actively undertake project risks, and achieve synergy effects of PPP projects.

(2) We analyzed the synergistic effect of the PPP project and the synergy effect of enterprise cooperation. Based on the enterprise cooperative output model, the total output model of PPP project is proposed. Considering the efforts and synergy of both parties, a PPP project incentive model based on synergy is constructed to study the incentive problem of PPP projects with synergistic effects. The research results show that with the improvement of the synergy between project participants, the government will increase incentives for social capital participants and project participants will improve their efforts and achieve synergies in PPP projects. Through the cooperation of both parties, the total income of PPP projects is increased.
(3) Considering the efforts of both parties and the synergy effect of PPP projects, the efforts of social capital participants are divided into compliance behaviors and speculation behaviors, introducing government supervision and punishment and constructing a PPP project supervision and punishment model based on synergy effect. The research results show that the government chooses social capital participants with complementary advantages to form synergy; with the increase of synergy, the government needs to increase the incentive intensity, improve the performance behavior of social capital participants, curb their speculation, and promote the two sides. Due to the increased synergy and the willingness of social capital participants to increase cooperation and reduce speculation, the government should reduce the intensity of supervision and punishment.

\section{Data Availability}

No data were used to support this study.

\section{Conflicts of Interest}

The authors declare that they have no conflicts of interest.

\section{Acknowledgments}

This work was supported by the Research on the Mechanism of AFRE as the Intermediary Target of Monetary Policy (no. BS201903), Wealth Management Characteristic Construction Research Project of Shandong Technology and Business University (no. 2019ZBKY099), and Shandong Provincial Natural Science Foundation, China (no. ZR2020QG035).

\section{References}

[1] W. Wu, Y. Liu, C. H. Wu, and S. B. Tsai, “An empirical study on government direct environmental regulation and heterogeneous innovation investment," Journal of Cleaner Production, vol. 254, Article ID 120079, 2020.

[2] J. Yuan, W. Li, J. Guo, X. Zhao, and M. Skibniewski, "Social risk factors of transportation PPP projects in China: a sustainable development perspective," International Journal of Environmental Research and Public Health, vol. 15, no. 7, p. 1323, 2018.

[3] L. Fabisiak, "Web service usability analysis based on user preferences," Journal of Organizational and End User Computing, vol. 30, no. 4, pp. 1-13, 2018.

[4] H. Wu, P. Tiwari, S. S. Han, and T. K. Chan, "Brownfield risk communication and evaluation," Journal of Property Research, vol. 34, pp. 1-18, 2017.

[5] C. P. Medeiros, M. H. Alencar, and A. T. de Almeida, "Multidimensional risk evaluation of natural gas pipelines based on a multicriteria decision model using visualization tools and statistical tests for global sensitivity analysis," Reliability Engineering \& System Safety, vol. 165, pp. 268-276, 2017.

[6] X. Zhang, Y. Zhang, Z. Liu, and J. Liu, "Analysis of heat transfer and flow characteristics in typical cambered ducts," 
International Journal of Thermal Sciences, vol. 150, Article ID 106226, 2020.

[7] F. Xiao and W. Ding, "Divergence measure of pythagorean fuzzy sets and its application in medical diagnosis," Applied Soft Computing, vol. 79, pp. 254-267, 2019.

[8] L. Wang, H.-Y. Zhang, J.-Q. Wang, and L. Li, "Picture fuzzy normalized projection-based vikor method for the risk evaluation of construction project," Applied Soft Computing, vol. 64, pp. 216-226, 2018.

[9] V. Mohagheghi, S. M. Mousavi, B. Vahdani, and M. R. Shahriari, "R\&D project evaluation and project portfolio selection by a new interval type-2 fuzzy optimization approach," Neural Computing \& Applications, vol. 28, no. 12, pp. 3869-3888, 2017.

[10] M. Orouskhani and D. Shi, "Fuzzy adaptive cat swarm algorithm and borda method for solving dynamic multi-objective problems," Expert Systems, vol. 35, no. 4, pp. e12286.1-e12286.15, 2018.

[11] T. Grubljesic, P. S. Coelho, and J. Jaklic, "The shift to socioorganizational drivers of business intelligence and analytics acceptance," Journal of Organizational and End User Computing, vol. 31, no. 2, pp. 37-64, 2019.

[12] M. Orouskhani, M. Teshnehlab, and M. A. Nekoui, "Integration of cat swarm optimization and borda ranking method for solving dynamic multi-objective problems," International Journal of Computational Intelligence \& Applications, vol. 15, no. 3, pp. 267-289, 2016.

[13] G. Khatwani and P. R. Srivastava, "Impact of Information technology on information search channel selection for consumers," Journal of Organizational and End User Computing, vol. 30, no. 3, pp. 63-80, 2018.

[14] W. Zhang and Y. Zhang, "Research and application of the robust fuzzy tree method," Journal of Chinese Society of Power Engineering, vol. 37, no. 5, pp. 401-407, 2017.

[15] H. P. Ren, H. H. Chen, W. Fei, and D. F. Li, "A magdm method considering the amount and reliability information of interval-valued intuitionistic fuzzy sets," International Journal of Fuzzy Systems, vol. 19, no. 3, pp. 1-11, 2016.

[16] X. Sun, H. Zhang, W. Meng, R. Zhang, K. Li, and T. Peng, "Primary resonance analysis and vibration suppression for the harmonically excited nonlinear suspension system using a pair of symmetric viscoelastic buffers," Nonlinear Dynamics, vol. 94, no. 2, pp. 1243-1265, 2018.

[17] T. Yang, Q. Liu, J. Jing, Y. Yan, and Z. Zou, “A framework for identification of maintenance significant items in reliability centered maintenance," Energy, vol. 118, pp. 1295-1303, 2017.

[18] T. Sang-Bing, W. Yu-Min, and C. Kuan-Yu, "Evaluating green suppliers from green environmental perspective," Environment and Planning B-Planning \& Design, vol. 43, no. 5, pp. 941-959, 2016.

[19] A. M. Al-Momani, M. A. Mahmoud, and M. S. Ahmad, "Factors that influence the acceptance of internet of things services by customers of telecommunication companies in Jordan," Journal of Organizational and End User Computing, vol. 30, no. 4, pp. 51-63, 2018.

[20] L. Z. Zhang, M. Mouritsen, and J. R. Miller, "Role of perceived value in acceptance of "bring your own device" policy," Journal of Organizational and End User Computing, vol. 31, no. 2, pp. 65-82, 2019. 